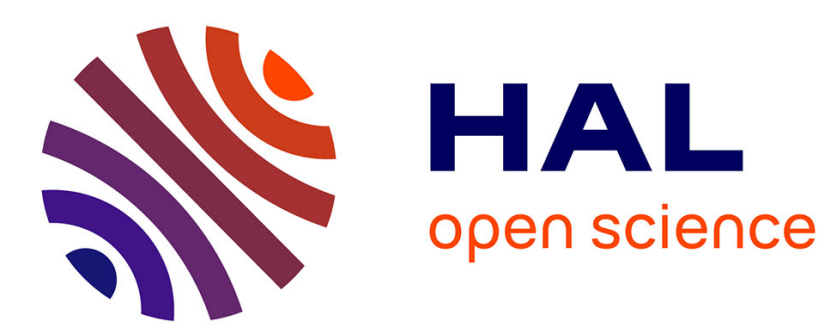

\title{
Experimental investigation on pore size effect on the linear viscolelastic properties of acoustic foams
}

\author{
Mickael Deverge, Lazhar Benyahia, Sohbi Sahraoui
}

\section{To cite this version:}

Mickael Deverge, Lazhar Benyahia, Sohbi Sahraoui. Experimental investigation on pore size effect on the linear viscolelastic properties of acoustic foams. Journal of the Acoustical Society of America, 2009, 126 (3), pp.EL93-EL96. 10.1121/1.3186799 . hal-00433859

\section{HAL Id: hal-00433859 \\ https://hal.science/hal-00433859}

Submitted on 20 Nov 2009

HAL is a multi-disciplinary open access archive for the deposit and dissemination of scientific research documents, whether they are published or not. The documents may come from teaching and research institutions in France or abroad, or from public or private research centers.
L'archive ouverte pluridisciplinaire HAL, est destinée au dépôt et à la diffusion de documents scientifiques de niveau recherche, publiés ou non, émanant des établissements d'enseignement et de recherche français ou étrangers, des laboratoires publics ou privés. 


\title{
Pore size and viscoelasticity of acoustic foams \\ Mickaël Deverge
}

LAUM, CNRS, Université du Maine, Av. O. Messiaen, 72085 Le Mans, France

mickael.deverge@univ-lemans.fr

Lazhar Benyahia

PCI CNRS, Université du Maine, Av. O. Messiaen, 72085 Le Mans, France

lazhar.benyahia@univ-lemans.fr

Sohbi Sahraoui

LAUM, CNRS, Université du Maine, Av. O. Messiaen, 72085 Le Mans, France

sohbi.sahraoui@univ-lemans.fr

\begin{abstract}
We present linear viscoelastic measurement on a large frequency range $\left(10^{-2}\right.$ to $\left.10^{8} \mathrm{~Hz}\right)$ for cross-linked polymer open cell foams of same density and different pore size. This extend of frequency range is obtained by the validation of Time-Temperature Superposition (TTS) principle, commonly used with polymers. At higher frequencies, the shear moduli are independent on the pore size. In acoustical insulation range $(1 \mathrm{~Hz}-16 \mathrm{kHz})$, the shear moduli decrease with the foams pore size.
\end{abstract}

PACS numbers: 43.35. Mr, 43.50. Gf, 43.20. Ye

\section{Introduction}

The use of cellular materials based on polymers foam shows an increase interest these last decades, particularly in automotive industry for acoustic absorption ${ }^{1}$. Several methods for mechanical characterisation in the linear domain were developed. Three principal measurement techniques can be currently distinguished:

- quasi-static methods, limited to low frequencies; they offer an excellent frequency resolution ${ }^{2}$,

- dynamic methods, based on sample resonance; they make it possible to cover an important frequency range but with a poor frequency resolution, moreover fluid-structure coupling effects cannot be neglected when measurements are not carried out in vacuum ${ }^{3}$,

- acoustic methods, based on acoustical excitation and Rayleigh wave velocity measurements ${ }^{4}$.

An alternative to extend a frequency range measurement with an enhanced resolution is the use of TimeTemperature Superposition (TTS) principle, largely validated on polymers ${ }^{5,6}$. Indeed, H. LEADERMAN ${ }^{7}$ noted that the behaviour of a viscoelastic material at high temperature and short time is equivalent to its behaviour at lower temperature and longer time. Thus, increasing temperature and reducing frequency (or inversely) is a similar operation for these materials. In another word, this principle is based on the equivalence of temperature and frequency variations of some physical variables, such as shear moduli or viscosity. The application of TTS leads to a master curve, considered at a reference temperature $T_{\text {ref }}$, where the frequency is considerably extended by multiplying the frequency with a shift factor $a_{T}$ depending on the temperature. However the TTS principle cannot be applied to all materials. It is not possible to determine a priori if a material satisfy this principle before carrying out the test. Usually, TTS principle is not satisfied when two relaxation of different nature occur on the studied frequency range ${ }^{5}$. More details on this approach and on the master curve building can be found in previous papers. ${ }^{5,7,8}$

Recently, the TTS method is partially validated, on a reduced frequency range, by SFAOUI ${ }^{9}$, then ETCHESSAHAR ${ }^{8}$ on polymer foams. In the present work, we extend this method for open-cells foams to a wider frequency range (from $10^{-2}$ to $10^{8} \mathrm{~Hz}$ ). Actually, we analyse the effect of pore size on the linear viscoelastic properties of opencells foams with same density and based on the same cross-linked polymer.

\section{Material and method}

A full open cell foams are provided by Recticel ${ }^{\circledR}$ company. We selected 4 references from Bulpren ${ }^{\circledR} \mathrm{S}$ family based on cross-linked polyurethane and used as heat or acoustic insulators. The samples have the same chemical composition, the same porosity $(0.98)$ and the same mass density $\left(29\right.$ to $\left.31 \mathrm{~kg} / \mathrm{m}^{3}\right)$. They only differ by their pore size: S20 (1.01-1.69 mm), S30 $(0.72-1.01 \mathrm{~mm}), \mathrm{S} 60(0.39-0.5 \mathrm{~mm}), \mathrm{S} 90(0.27-0.32 \mathrm{~mm})$. For rheological measurements, cylindrical samples (diameter $45 \mathrm{~mm}$, height $10 \mathrm{~mm}$ ) were carefully cut.

Dynamic measurements of complex shear modulus $G^{*}$ were carried out with a commercial apparatus from Rheometrics Scientific (RDA2) equipped with a heating and cooling oven. The choice of a non-resonant torsion technique ensures an excellent frequency resolution and allows simplified assumptions: non coupling fluidstructure effects, Poisson's ratio $v$ is real and independent of the frequency ${ }^{10}$. To avoid any slip phenomenon, polyurethane foam samples are stocked by a two-sided adhesive tape between the two parallel aluminium plates. 
The upper side of samples remains fixed and is connected to a torque sensor. The lower side of samples is harmonically excited in torsion mode with a constant and controlled angular frequency $\omega: \gamma(t)=\gamma_{0} \sin (\omega t)$. $\gamma(t)$ is the imposed strain and $\gamma_{0}$ the fixed imposed strain amplitude. From the torque we deduce a tress $\sigma(t)=\sigma_{0} \sin (\omega t+\delta)$ where $\sigma_{0}$ is the stress amplitude and $\delta$ the phase angle. The stress equation can be written as $\sigma(t)=G^{\prime}(\omega) \gamma_{0} \sin (\omega t)+G^{\prime \prime}(\omega) \gamma_{0} \cos (\omega t)$ where $G^{\prime}(\omega)$ and $G^{\prime \prime}(\omega)$ represent respectively the elastic and loss shear modulus. It reads than, at a given temperature, these moduli depend only on frequency and are directly connected to the amplitudes $\sigma_{0}$ and $\gamma_{0}$ as well as to the phase angle $\delta$ by the following equation:

$$
G^{*}(\omega)=G^{\prime}(\omega)+i G^{\prime \prime}(\omega) \quad \text { with } \quad G^{\prime}(\omega)=\frac{\sigma_{0}}{\gamma_{0}} \cos (\delta) \text { and } \quad G^{\prime \prime}(\omega)=\frac{\sigma_{0}}{\gamma_{0}} \sin (\delta)
$$

where $\mathrm{i}$ is the complex number $\left(i^{2}=-1\right)$.

Measurements were repeated at various temperatures T ranging from $20^{\circ} \mathrm{C}$ to $-25^{\circ} \mathrm{C}$. A latency of 10 minutes is necessary before each temperature measurement in order to guarantee temperature homogeneity in sample. At each temperature, the frequency sweep was fixed between 0.016 and $16 \mathrm{~Hz}$ in the linear regime ${ }^{5}$ where material response remains independent of applied shear strain $\gamma_{0}$. Master curves of shear moduli were obtained using time-temperature equivalence principle at $\mathrm{T}_{\text {ref }}=20^{\circ} \mathrm{C}$.

\section{Results and discussion}

The shear moduli are plotted versus frequency on figure 1 for the sample S20 at different temperatures above the glass transition of the polyurethane $\left(\mathrm{T}_{\mathrm{g}}=-25^{\circ} \mathrm{C}\right)$. Either the elastic $\left(\mathrm{G}^{\prime}\right)$ and the viscous $\left(\mathrm{G}^{\prime \prime}\right)$ modulus show a small dependency on the explored frequency range. In maximum, the moduli are increased by a factor 5 between $10^{-2}$ and $20 \mathrm{~Hz}$.

Figure 2 presents master curves at a reference temperature $T_{\text {ref }}=20^{\circ} \mathrm{C}$ for all Bulpren $\mathrm{S}$ foams of this study. The construction of master curves is obtained by multiplying the frequency by a factor $\mathrm{a}_{\mathrm{T}}$ and the moduli by a factor $\mathrm{b}_{\mathrm{T}}$. The factors $\mathrm{a}_{\mathrm{T}}$ (not chosen) are close the one obtained in previous study ${ }^{8}$ and are independent of pore size. $\mathrm{b}_{\mathrm{T}}$ are close to unity and reflect the mass density change with temperature.

All foams show a similar dependence in the range of explored frequency. In particular, at high frequencies, the moduli are identical and independent on the pore size. Since the density of all foams tested here are equal, the moduli at high frequency depend on the volume fraction of the polymer. There is no effect of the macroscopic structure (various pore sizes for various foams) but only response of polymer which composes skeleton and is identical for the foams

At low frequencies $(1 \mathrm{~Hz}-16 \mathrm{kHz})$, the shear moduli decreases slightly with the increase of the pore size of foams. The dependence of the elastic modulus G' versus the pore size of the foams, at lower frequency, is reported in the insert of figure 2. Similar observations were reported in the literature but the opinions steel diverges on how the elastic modulus of foams should depend on the pore size ${ }^{11,12}$. We may mention that in the range of the explored pore size of foams in this study, there is no significant difference between previous models in adjusting our experimental values. In our case, we found that $G^{\prime}$ at lower frequency may be related to the foams pore size by a simple empirical power law:

$$
G^{\prime} \propto 1 / \sqrt{\text { poresize }}
$$

\section{Conclusion}

In this work, complex shear modulus $G^{*}$ was determined on a large frequency range (from $10^{-2}$ to $10^{8} \mathrm{HZ}$ ) by using a quasi-static method coupled with time-temperature superposition principal. The TTS principle was generalized here to cross-linked polymer open-cell foams and on a large frequency range. We show that TTS is useful with the studied polymer foams since the accurate of measurement is increased. The construction of shear moduli master curves reveals that a) at high frequency, G' and G" are independent on the pore size of foams with identical mass density since the moduli depend on the skeleton of foams at high frequency, $b$ ) at low frequencies $(1 \mathrm{~Hz}-16 \mathrm{kHz}), \mathrm{G}^{\prime}$ and G" decrease with decreasing frequency and more rapidly when the pore size of foams increases. 


\section{References}

${ }^{1}$ R. Deng, P. Davies, and A.K. Bajaj, Flexible polyurethane foam modelling and identification of viscoelastic parameters for automotive seating applications. Journal of Sound and Vibration, 2003. 262(3): p. 391-417.

${ }^{2}$ S. Sahraoui, , E. Mariez, and M. Etchessahar, Mechanical testing of polymeric foams at low frequency. Polymer Testing, 2001.

20(1): p. 93-96.

${ }^{3}$ T. Pritz, , Dynamic Young modulus and loss factor of plastic foams for impact sound isolation. Journal of Sound and Vibration, 1994. 178(3): p. 315-322.

${ }^{4}$ J.F. Allard, M. Henry, L. Boeckx, P. Leclaire, and W. Lauriks, Acoustical measurement of the shear modulus for thin porous layers. Journal of the Acoustical Society of America, 2005. 117(4): p. 1737-1743.

${ }_{5}$ J.D.Ferry, , Viscoelastic properties of polymers. John Wiley ed. 1961, New-York: John Wiley.

${ }^{6}$ M.L.Williams, R.F. Landel, and J.D. Ferry,. The temperature dependence of relaxation mechanisms in amorphous polymers and other glass-forming liquids. Journal of the American Chemical Society, 1955. 77(14): p. 3701-3707.

${ }^{7}$ H. Leaderman, , Textile Materials and the Time Factor: I. Mechanical Behavior of Textile Fibers and Plastics. Textile Research Journal, 1941. 11: p. 171-193.

${ }^{8}$ M. Etchessahar, S. Sahraoui, L. Benyahia, and J.F. Tassin, Frequency dependence of elastic properties of acoustic foams. Journal of the Acoustical Society of America, 2005. 117(3): p. 1114-1121.

${ }^{9}$ A. Sfaoui, On the viscoelasticity of the polyurethane foam. Journal of the Acoustical Society of America, 1995. 97(2): p. 10461052.

${ }^{10}$ T. Pritz, , Measurement methods of complex Poisson's ratio of viscoelastic materials. Applied Acoustics, 2000. 60(3): p. 279-292.

${ }^{11}$ K. Li, X.L. Gao, and A.K. Roy, Micromechanics model for three-dimensional open-cell foams using a tetrakaidecahedral unit cell and Castigliano's second theorem. Composites Science and Technology, 2003. 63(12): p. 1769-1781.

${ }^{12} \mathrm{E}$. Olevsky and A. Molinari, Kinetics and stability in compressive and tensile loading of porous bodies. Mechanics of Materials, 2006. 38(4): p. 340-366. 


\section{Captions of figures}

Figure 1. (a) Real part G' and (b) imaginary part G" of shear modulus of Bulpren S20 foam, subjected to a strain of $0.05 \%$, at various temperatures as indicated in the figure.

Figure 2. Master curves for whole Bulpren S foams: Real $G^{\prime}$ (closed symbols) and imaginary $G^{\prime \prime}$ parts (open symbols) of shear moduli, at reference temperature $T_{r e f}=20^{\circ} \mathrm{C}$. The insert represents the elastic shear modulus $G^{\prime}$ (at $10^{-2} \mathrm{~Hz}$ ) versus mean of pore size in a semi log scale. The solid line represents Eq. (2). 

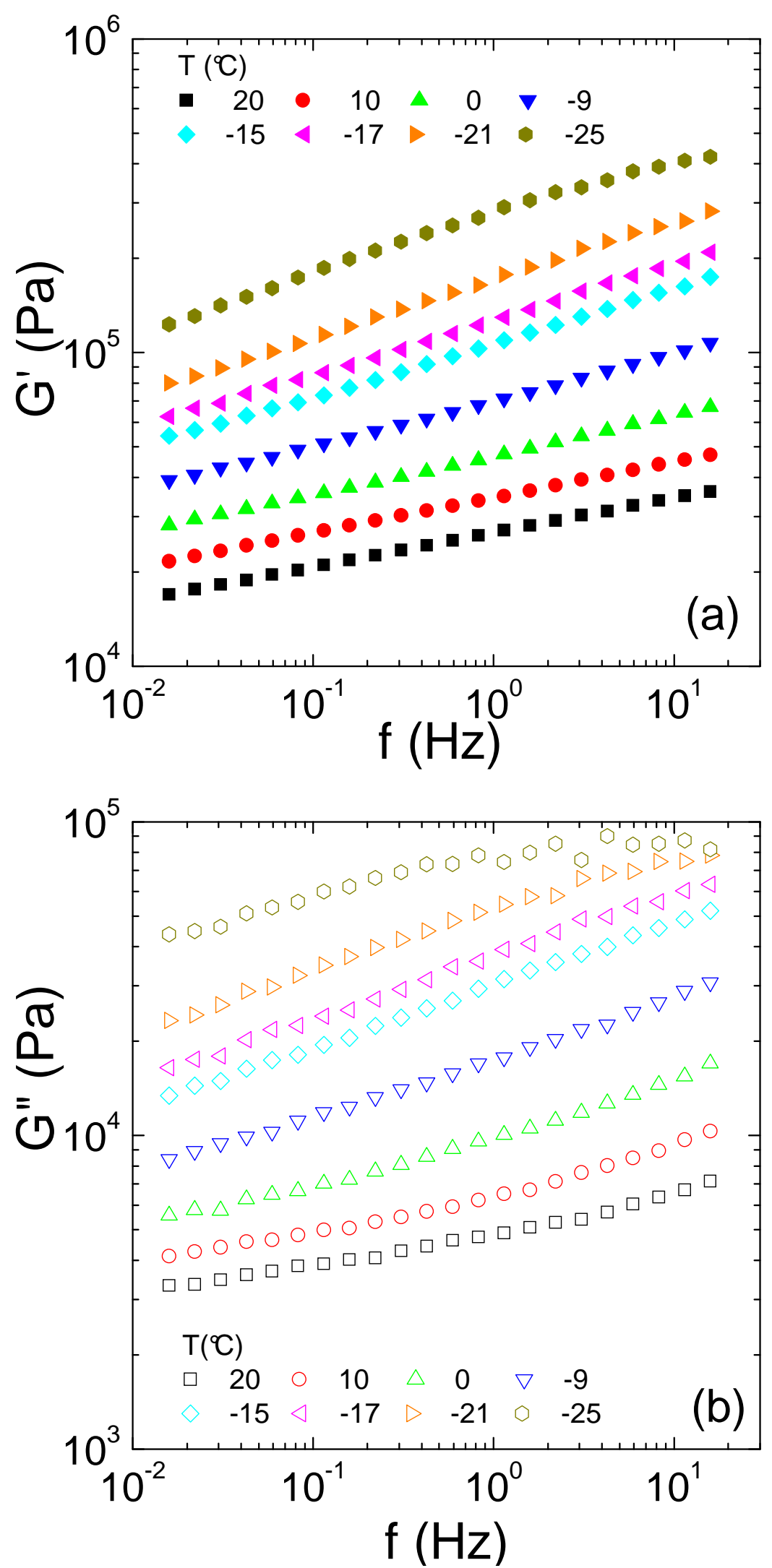

Figure 1 


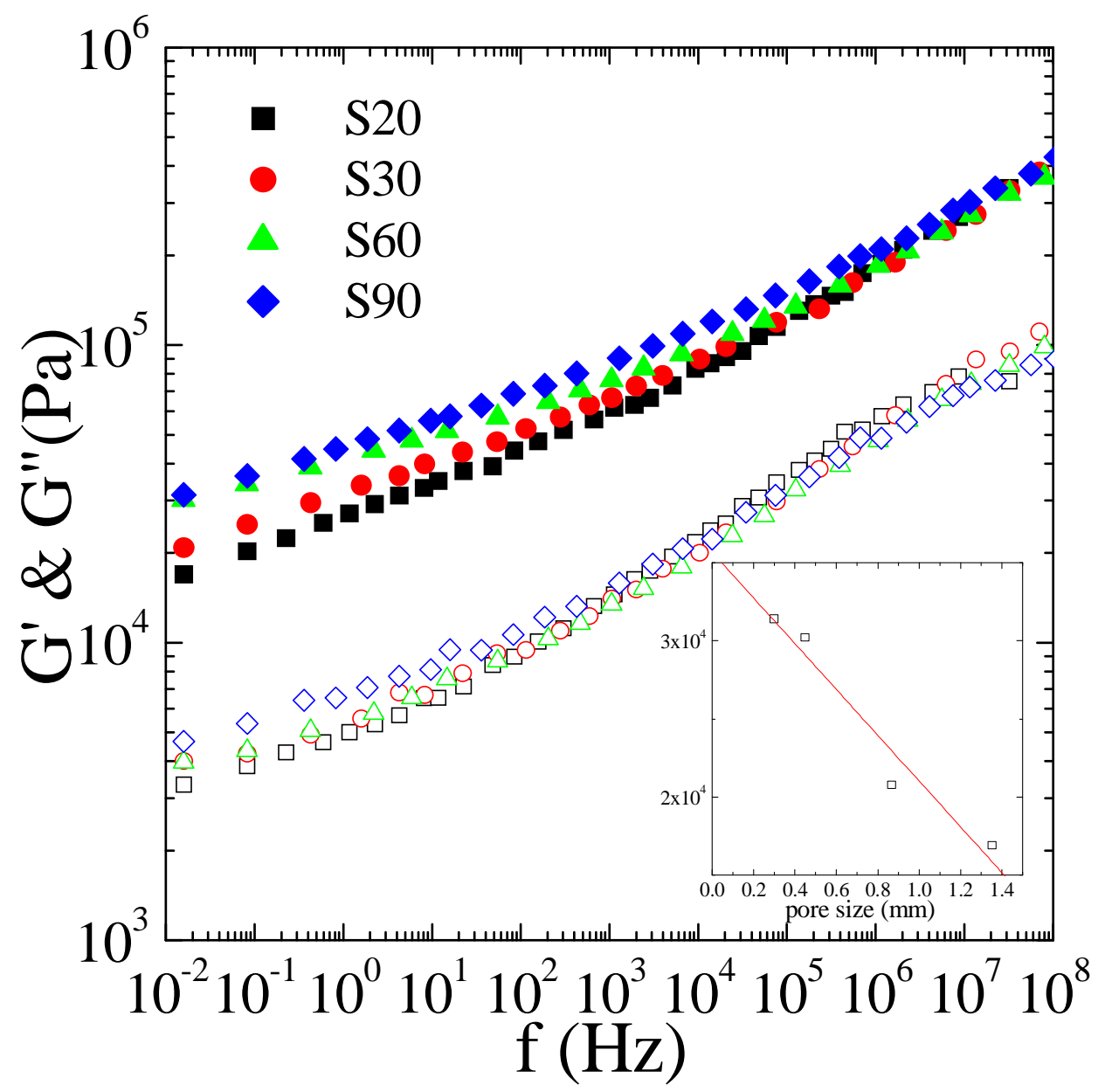

Figure 2 